\title{
Ternary Self-Assembly of Ordered Metal Oxide-Graphene Nanocomposites for Electrochemical Energy Storage
}

\author{
Donghai Wang, ${ }^{+, \S}$ Rong Kou, ${ }^{\dagger}$ Daiwon Choi, ${ }^{+}$Zhenguo Yang, ${ }^{+}$Zimin Nie, ${ }^{\dagger}$ Juan Li, ${ }^{\dagger}$ Laxmikant V. Saraf, ${ }^{+}$ \\ Dehong Hu, ${ }^{+}$Jiguang Zhang, ${ }^{\dagger}$ Gordon L. Graff, ${ }^{+}$Jun Liu, ${ }^{+, *}$ Michael A. Pope, ${ }^{\neq}$and Ilhan A. Aksay ${ }^{\ddagger, *}$ \\ ${ }^{\dagger}$ Pacific Northwest National Laboratory, Richland, Washington 99352 and ${ }^{\ddagger}$ Princeton University, Princeton, New Jersey 08544. ${ }^{5}$ Present address: Department of \\ Mechanical and Nuclear Engineering, The Pennsylvania State University, University Park, Pennsylvania 16802.
}

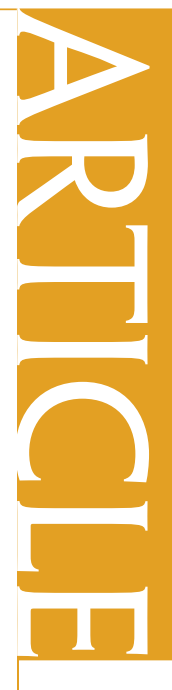

$\mathrm{N}$ anocomposites have attracted wide attention because of their potential to combine desirable properties of different nanoscale building blocks to improve mechanical, optical, electronic, or magnetic properties. ${ }^{1-6}$ Most traditional synthesis approaches of nanocomposites rely on mechanical or chemical mixing and produce a random distribution of the constitutive phases. To address these problems, several groups recently investigated layer-by-layer deposition and other techniques to prepare layered nanocomposites with ceramics, clays, and graphite oxide nanoplatelets, ${ }^{7-9}$ but these methods are lacking in nanoscale spatial precision and are time-consuming and difficult for bulk-materials synthesis. On the other hand, biological systems abound with nanocomposites that possess well-controlled architectures based on multiple scale and multifunctional building blocks. ${ }^{10}$ One powerful approach to achieve similar control is to use amphiphilic polymer or surfactant to direct the self-assembly of nanostructured metal oxides, semiconductors, and polymer materials. ${ }^{11-15}$ There has been a growing interest in incorporating functional components, such as functional groups, polymers, and nanoparticles, into the self-assembled nanostructures, but success has been limited to two-phase organic/inorganic hybrid materials, nanoparticles, or polymer-based nanocomposites. ${ }^{4,5,16,17}$

Recently, a range of nanoscale building blocks, including carbon nanotubes ${ }^{18-21}$ and graphene, ${ }^{22-24}$ have gained prominence. Graphene and graphene stacks (multilayer graphene), potentially low cost alternative materials to single-wall or multiwall carbon nanotubes, have unique electronic conductivity and mechanical

ABSTRACT Surfactant or polymer directed self-assembly has been widely investigated to prepare nanostructured metal oxides, semiconductors, and polymers, but this approach is mostly limited to two-phase materials, organic/inorganic hybrids, and nanoparticle or polymer-based nanocomposites. Self-assembled nanostructures from more complex, multiscale, and multiphase building blocks have been investigated with limited success. Here, we demonstrate a ternary self-assembly approach using graphene as fundamental building blocks to construct ordered metal oxide - graphene nanocomposites. A new class of layered nanocomposites is formed containing stable, ordered alternating layers of nanocrystalline metal oxides with graphene or graphene stacks. Alternatively, the graphene or graphene stacks can be incorporated into liquid-crystal-templated nanoporous structures to form high surface area, conductive networks. The self-assembly method can also be used to fabricate free-standing, flexible metal oxide-graphene nanocomposite films and electrodes. We have investigated the Li-ion insertion properties of the self-assembled electrodes for energy storage and show that the $\mathrm{SnO}_{2}-$ graphene nanocomposite films can achieve near theoretical specific energy density without significant charge/discharge degradation.

KEYWORDS: nanocomposite $\cdot$ ordered $\cdot$ graphene $\cdot$ li-ion battery

properties. ${ }^{25-27}$ Graphene-based nanocomposites with polymer, metal, or metal oxides have also shown unique mechanical, electronic, and electrochemical properties. ${ }^{23,28-35}$ We focus on the nanocomposites made of metal oxides (i.e., $\mathrm{SnO}_{2}$, $\mathrm{NiO}, \mathrm{MnO}_{2}$, and $\mathrm{SiO}_{2}$ ) that could have important applications for electrochemical energy storage ${ }^{36,37}$ The low conductivity and poor stability of such materials usually necessitate adding conductive phases to enhance electron transport and electrical contact of the active materials in the electrode of a Li-ion battery. In most of these studies, the approach used to prepare the composite materials has been mechanical mixing of metal oxides with conductive materials such as amorphous carbon, carbon nanotubes, and graphene. ${ }^{31,38}$ In spite of these studies, a well-controlled architecture of the conductive material and metal oxide is difficult to achieve because of improper
*Address correspondence to jun.liu@pnl.gov, iaksay@princeton.edu.

Received for review August 12, 2009 and accepted February 09, 2010.

Published online February 25, 2010. $10.1021 / \mathrm{nn} 901819 n$

() 2010 American Chemical Society 
(A)

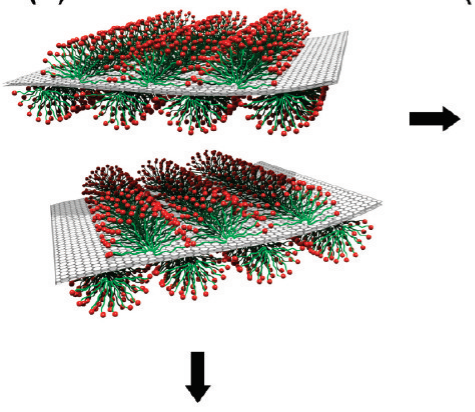

(B)

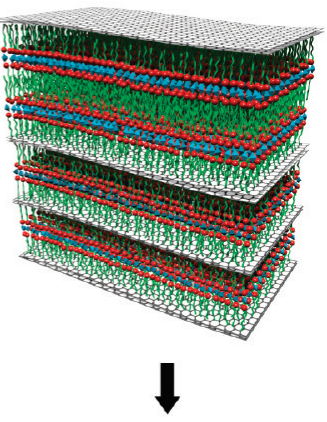

(D)

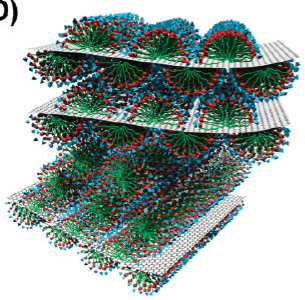

(C)

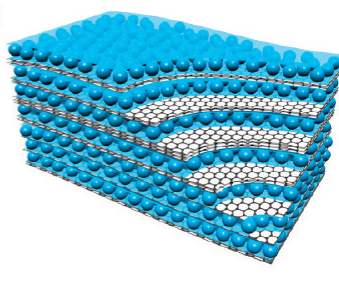

Figure 1. Schematic illustrations of the ternary self-assembly approach to ordered metal oxide-graphene nanocomposites. (A) Graphene or graphene stacks, which are used as the substrate instead of graphite. Adsorption of surfactant hemimicelles on the surfaces of the graphene or graphene stacks causes its dispersion in surfactant micelles in an aqueous solution. (B) The self-assembly of anionic sulfonate surfactant on the graphene surface with oppositely charged metal cation (e.g., $\mathrm{Sn}^{2+}$ ) species and the transition into the lamella mesophase toward the formation of $\mathrm{SnO}_{2}$ - graphene nanocomposites, where hydrophobic graphenes are sandwiched in the hydrophobic domains of the anionic surfactant. (C) Metal oxide-graphene layered nanocomposites composed of alternating layers of metal oxide nanocrystals and graphene/ graphene stacks after crystallization of metal oxide and removal of the surfactant. (D) Self-assembled hexagonal nanostructure of metal oxide precursor (e.g., silicate) with nonionic surfactants (e.g., Pluronic P123) on graphene stacks.

integration of multiple phases by mechanical mixing methods.

We contend that strategies to coerce multiple phases of metal oxides and nanoscale building blocks such as graphene into deterministic nanostructured materials by self-assembly will open new opportunities for designing and synthesizing multifunctional nanocomposite materials. As a proof-of-concept, we report a new approach based on the ternary self-assembly of metal oxides, surfactants, and graphene to produce well-controlled, ordered nanocomposites composed of metal oxide and graphene or graphene stacks. We show that this approach can be applied to a range of metal oxide materials and demonstrate that the electrochemical properties can be much improved.

We use functionalized graphene sheets (FGSs) prepared by the thermal expansion of graphite oxide. As prepared, the FGSs contain approximately $80 \%$ singlesheet graphene along with stacked graphene (graphene stacks) as described previously. ${ }^{39,40}$ Although it is possible to eliminate the stacked portion of the material by sedimentation methods, these stacks do not prevent us from accomplishing our goal of nanostructuring through ternary self-assembly. Pristine graphene

is intrinsically hydrophobic, and its surface chemistry is not compatible with many hydrophilic metal oxides. Many methods have been reported to modify the surface of graphene and to improve the dispersion in the composite materials, mostly through functionalization ${ }^{41-43}$ of oxidized graphene surfaces or by using surfactants, polymer, or aromatic molecules as dispersants. ${ }^{44-47}$ We prefer to work with surfactants since they not only assist the dispersion of the graphene material (graphene or stacked graphene) in aqueous media but also direct the self-assembly of metal oxides into nanostructures. The anionic surfactants we use first adsorb onto the surface of the $\mathrm{FGSS}^{39,48,49}$ to ensure that the graphene materials are dispersed in the hydrophobic domains of the surfactant micelles (Figure 1A). The surfactant micelles with the FGSs then become the fundamental building blocks for self-assembly. The surfactants assembled to the FGSs bind to the metal cations, forming an ordered nanocomposite (Figure 1B)..$^{50}$ The metal oxides are crystallized between FGSs, producing a new class of nanocomposites in which alternating layers of graphene/ graphene stacks and metal oxide nanocrystals are assembled into layered nanostructures (Figure 1C). Alternatively, metal oxides can self-assemble with the surfactant into a hexagonal mesophase on the surface of the graphene or stacked graphene by using a nonionic block copolymer surfactant, ${ }^{51,52}$ thus obtaining hexagonal mesoporous metal oxide-graphene nanocomposites (Figure 1D).

\section{RESULTS AND DISCUSSION}

The structures of the nanocomposites prepared with ternary self-assembly were characterized by transmission electron microscopy (TEM), X-ray diffraction (XRD), and scanning electron microscopy (SEM). Figure 2 shows cross-sectional TEM images of the nanostructures of alternating layers of metal oxides and graphene stacks in a $\mathrm{SnO}_{2}-$ graphene and $\mathrm{NiO}-$ graphene nanocomposite prepared in powder form. The crosssectional TEM image of the calcined $\mathrm{SnO}_{2}$ - graphene nanocomposite clearly shows multiple regularly spaced layers of $\mathrm{SnO}_{2}$ separated by graphene materials (Figure 2A). Each layer of $\mathrm{SnO}_{2}$ is about $3-5 \mathrm{~nm}$ thick and is rather uniform. A selected area electron diffraction (SAED, inset in Figure 2A) pattern suggests a typical crystal structure of cassiterite $\mathrm{SnO}_{2}$ (Joint Committee on Powder Diffraction Standards [JCPDS] No. 000-0024), which is consistent with the XRD results (Figure $\mathrm{S} 1$ ). The corresponding dark-field image from the (211) reflection of $\mathrm{SnO}_{2}$ (Figure 2B) confirms that the $\mathrm{SnO}_{2}$ layer is made out of 4-nm crystals. Two symmetrical but diffuse diffraction spots can also be observed on top of the (110) diffraction ring of the $\mathrm{SnO}_{2}$, which is attributed to the (0002) diffraction of graphite-like graphene stacks. The dark-field image (Figure 2C) from the (0002) diffraction indeed reveals some band structures of the 


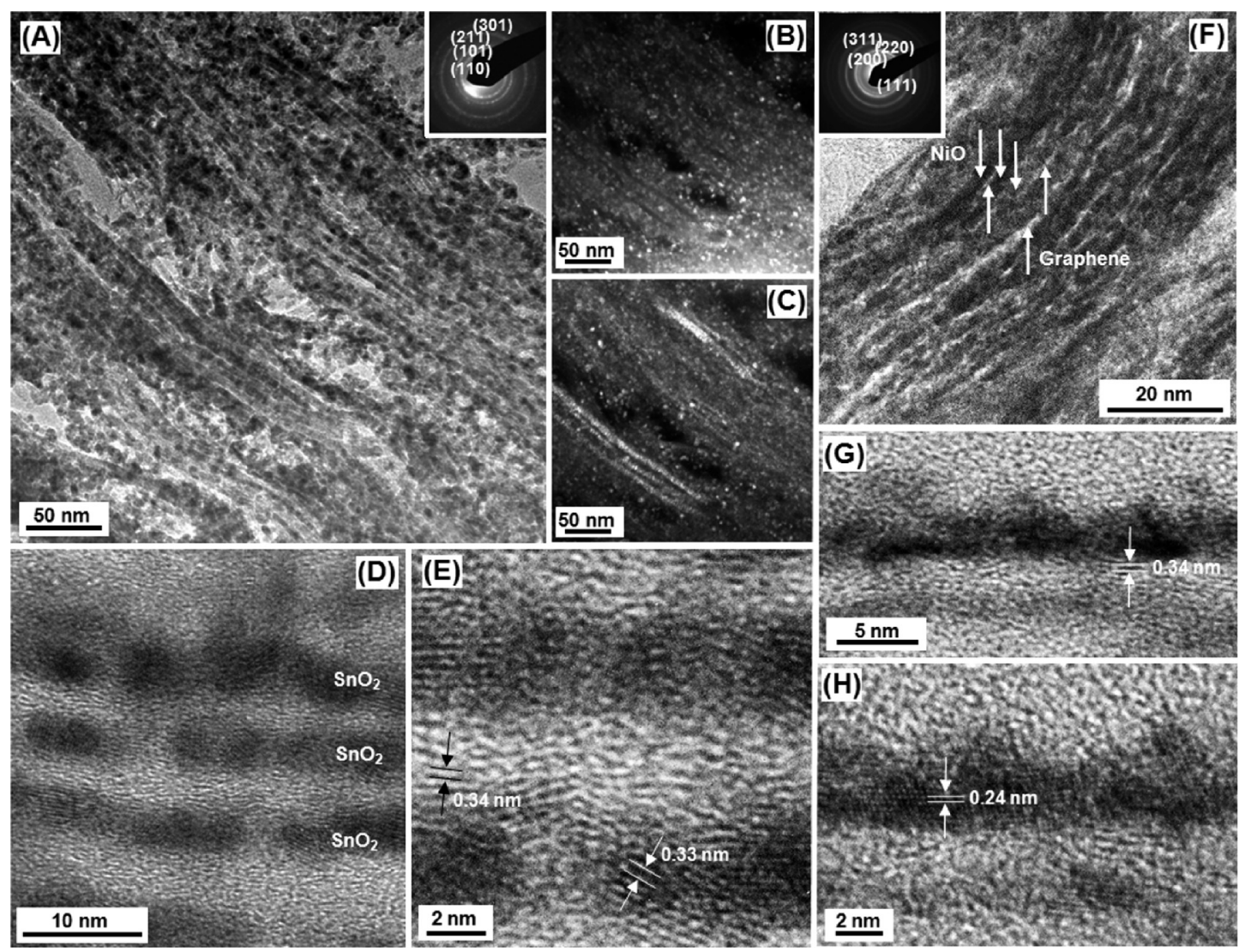

Figure 2. TEM images of calcined $\mathrm{SnO}_{2}-$ graphene (28 wt \% graphene) nanocomposite powder $(\mathrm{A}-\mathrm{E})$ and $\mathrm{NiO}-$ graphene (30 wt \% graphene) nanocomposites ( $\mathrm{F}-\mathrm{H}$ ). (A) Bright-field cross-sectional TEM image of the $\mathrm{SnO}_{2}-$ graphene nanocomposite powder showing layered structures. The inset is the corresponding SAED pattern. The ring pattern of diffraction shows polycrystalline cassiterite $\mathrm{SnO}_{2}$. The bright symmetrical diffraction spots located at the (110) rings of $\mathrm{SnO}_{2}$ correspond to (0002) diffraction of the oriented graphene stacks. (B) Dark-field TEM image obtained from the (211) diffraction ring of $\mathrm{SnO}_{2}$. (C) Dark-field TEM image obtained from the bright (0002) diffraction spots of the graphene stacks. (D) High-magnification TEM of $\mathrm{SnO}_{2}-$ graphene nanocomposites in panel A. The layered structure of $\mathrm{SnO}_{2}$ is composed of connected nanocrystalline $\mathrm{SnO}_{2}$ with a 4- to 5-nm diameter interspaced by graphene stacks. (E) High-resolution TEM image of the layered nanostructure of $\mathrm{SnO}_{2}-$ graphene nanocomposites in panel D. Lattice fringes of $0.33 \mathrm{~nm}$ corresponding to the $(110)$ plane of $\mathrm{SnO}_{2}$ and lattice fringes of $0.34 \mathrm{~nm}$ corresponding to the (0002) graphene stacks are marked in each layer. (F) Bright-field crosssectional TEM image of the NiO-graphene nanocomposite shows the nanocrystalline NiO layer (layer thickness of approximately $4 \mathrm{~nm}$ ) interspaced by the graphene stacks. The inset is the corresponding SAED pattern showing polycrystalline NiO. (G) High-resolution TEM image of $\mathrm{NiO}$-graphene nanocomposite showing graphene stacks between NiO layers. Lattice fringes of $0.34 \mathrm{~nm}$ corresponding to the (0002) graphene stacks are marked. $(\mathrm{H})$ High-resolution TEM image of NiOgraphene nanocomposite showing the lattice fringes of $\mathrm{NiO}$ along the (110) direction. Lattice fringes of $0.24 \mathrm{~nm}$ corresponding to (111) planes in $\mathrm{NiO}$ are marked.

graphene stacks separated by $\mathrm{SnO}_{2}$. A high-

magnification TEM image (Figure 2D) reveals that the $\mathrm{SnO}_{2}$ nanoparticles are connected to one another within the layer but separated from layer to layer by the graphene stacks containing 3-7 layers of graphene. Lattice fringes of both the (110) plane in 4-nm-diameter nanocrystalline $\mathrm{SnO}_{2}$ and the (0002) plane in graphene stacks are shown in the highresolution TEM image (Figure $2 \mathrm{E}$ ). It should be noted that the TEM observation is biased toward the stacked structure of graphene because a single graphene sheet is difficult, if not impossible, to image in the embedded cross-section TEM sample. Furthermore, we could not rule out the possibility of some degree of restacking of graphene into graphene stacks during the selfassembly process. Therefore, the final material most likely contains a mixture of graphene and graphene stacks. Nevertheless, an ordered, layered nanostructure with alternating metal oxide and the graphene materials is formed, even in the presence of the graphene stacks. We also obtained Raman spectra of the graphene and the $\mathrm{SnO}_{2}$ - graphene nanocomposite showing both $D$ and $G$ bands of graphene structure with a D/G band ratio of 0.65 and 0.61 , respectively (Supporting Informaiton, Figure S2). The Raman spectra in the nanocomposites are very similar to our previously reported data on Raman spectra of the functionalized graphene sheets. ${ }^{53}$ The D/G band ratio, the line width and line shape, and even the left and right line width for the $\mathrm{G}$ band (50 and $35 \mathrm{~cm}^{-1}$, respectively), are consistent with the previous observation. ${ }^{53}$ These results suggest that the graphene structure derived from the thermal expansion method is maintained in the nanocomposite materials. ${ }^{39,40}$ 

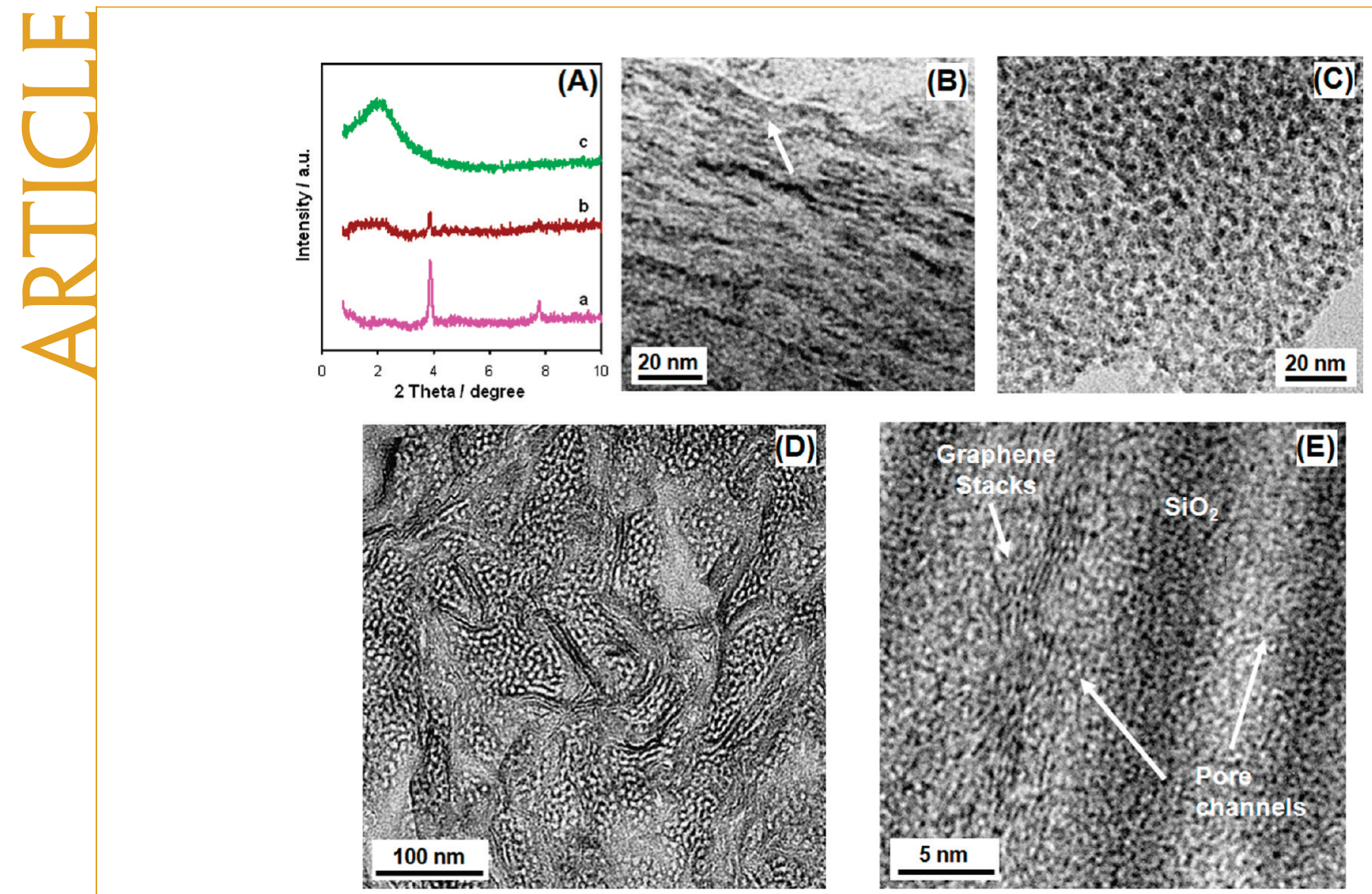

Figure 3. (A) Low-angle XRD patterns of the anionic surfactant $-\mathrm{SnO}_{2}-$ graphene precipitates after reaction times of 1 (a), 11 (b), and $16 \mathrm{~h}$ (c). Lamellar mesophase with (001) $d$-spacing of $2.3 \mathrm{~nm}$ is observed in the mixture. (B) Cross-sectional TEM image of anionic surfactant $-\mathrm{SnO}_{2}-$ graphene, which precipitates after a reaction time of $11 \mathrm{~h}$. The lamellar mesophase with (001) spacing of $2.4 \mathrm{~nm}$ is marked by an arrow. (C) Wormlike structure of $\mathrm{SnO}_{2}$ nanocrystals formed without adding the graphene. (D) Cross-sectional TEM image of mesoporous $\mathrm{SiO}_{2}-$ graphene nanocomposite powder $\left(30 \mathrm{wt} \% \mathrm{SiO}_{2}\right)$. Partially ordered mesoporous silica layers (4-5 mesoporous layers) are observed on the surface of graphene stacks following the contour of wrinkled graphene stacks. (E) High-resolution TEM image of the $\mathrm{SiO}_{2}-$ graphene nanocomposite powder in panel D. Graphene stacks are covered with hexagonal mesoporous silica.

Layered nanostructures with alternating layers of metal oxide and graphene stacks are also observed in the $\mathrm{NiO}-$ graphene (Figure $2 \mathrm{~F}$ and Supporting Information, Figure S1)) and $\mathrm{MnO}_{2}$ - graphene nanocomposites (Supporting Information, Figure S3). Lattice fringes of the (0002) plane in the graphene stacks and the (111) plane in the 5-nm-thick nanocrystalline $\mathrm{NiO}$ layer can be observed in high-resolution TEM images (Figure $2 \mathrm{G}, \mathrm{H}$ ). Our previous work did not show the formation of a layered structure with $\mathrm{TiO}_{2}{ }^{30}$ which is most likely due to a lower graphene concentration (less than $1 \mathrm{wt}$ $\%)$ and the fast crystal growth of $\mathrm{TiO}_{2}$ under similar reaction conditions.

Previous experimental and theoretical studies have suggested that anionic surfactant molecules adsorb on a graphite surface to form hemicylindrical micelle aggregates. ${ }^{54}$ Thus, the anionic surfactant can disperse the graphene or graphene stacks in the hydrophobic domains of the surfactant micelles to form a colloidal dispersion (Supporting Information, Figure S4). However, when the metal oxide precursor (e.g., $\mathrm{SnO}_{2}$ precursor) was added to the solution, a black precipitate with a lamellar nanostructure was obtained, as revealed by the XRD pat- tern (Figure 3A). Such a transition from rodlike micelles to lamellar nanostructures is not fully understood, but may be caused by the metal cation binding with the anionic surfactant head groups, which reduces the net charge and the effective headgroup size, favoring the formation of the lamellar mesophase. ${ }^{55}$

A hydrothermal reaction causes the crystallization of $\mathrm{SnO}_{2}$ between the separated graphene or graphene stacks and causes the long-range order produced by self-assembly to degrade (Figure $3 \mathrm{~A}$ ), but the overall lamellar nanostructures can be still observed in the TEM image (marked in Figure 3B) with an adjacent layer distance of $2.4 \mathrm{~nm}$, which is consistent with the (001) $d$-spacing $(2.3 \mathrm{~nm})$ of the lamellar mesophase observed in the XRD pattern (Figure 3A). Finally, calcination results in the decomposition and removal of the surfactants and further growth of $\mathrm{SnO}_{2}$ nanocrystals, forming an interconnected nanocrystalline $\mathrm{SnO}_{2}$ layer between the graphene stacks. By comparison, only wormlike nanoporous structures are observed in the absence of graphene over the reaction period, ${ }^{56,57}$ which is confirmed by TEM (Figure 3C) and XRD investigation (Supporting Information, Figure S5). 

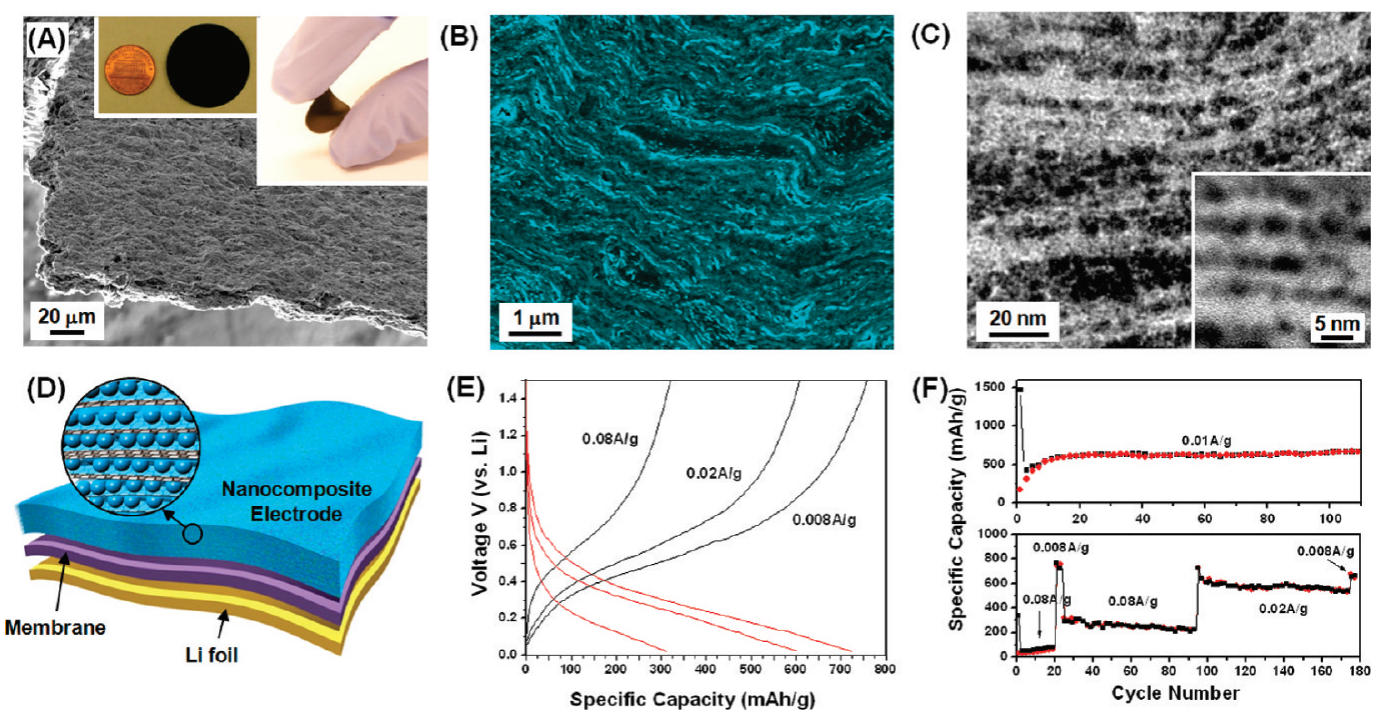

Figure 4. (A) Side-view SEM image of a self-assembled free-standing $\mathrm{SnO}_{2}-$ graphene nanocomposite (40 wt \% graphene) electrode $15 \mu \mathrm{m}$ thick. Photographs in the inset show a disklike $3 \mathrm{~cm}$ diameter $\mathrm{SnO}_{2}-$ graphene nanocomposite electrode on the left and a folded electrode on the right. (B) High-magnification cross-sectional SEM image of the free-standing $\mathrm{SnO}_{2}$-graphene nanocomposite electrode. The electrode is composed of well-packed wavy layers interspaced by the loosely packed layers through almost the entire cross section. (C) Cross-sectional TEM images of a $\mathrm{SnO}_{2}$ - graphene nanocomposite film. Inset shows high-resolution TEM image in the nanocomposite film with alternating layers of nanocrystalline $\mathrm{SnO}_{2}$ and graphene materials. (D) A Li-ion battery configuration directly using a freestanding metal oxide-graphene nanocomposite film as an electrode. The graphene materials in the layered nanostructures function as both current collector and conductive additives in the anode. (E) Charge/discharge profiles of a $\mathrm{SnO}_{2}$ - graphene nanocomposite electrode ( $40 \mathrm{wt} \%$ graphene) between 0.02 and $1.5 \mathrm{~V}$ at a current density of 0.008 , 0.02 , and $0.08 \mathrm{~A} / \mathrm{g}$, respectively. (F) (Top) Specific capacity of $\mathrm{SnO}_{2}$ as a function of charge/discharge cycles in the $\mathrm{SnO}_{2}-$ graphene nanocomposite electrode at a current density of $0.01 \mathrm{~A} / \mathrm{g}$. (Bottom) Specific capacity of $\mathrm{SnO}_{2}$ as a function of charge/discharge cycles in the $\mathrm{SnO}_{2}$-graphene nanocomposite at different charge/discharge current densities of $0.008,0.08$, and $0.02 \mathrm{~A} / \mathrm{g}$, respectively. Note that the nanocomposite electrode is precycled for 20 cycles at $0.08 \mathrm{~A} / \mathrm{g}$ to improve the electrolyte wetting and then cycled at $0.008 \mathrm{~A} / \mathrm{g}$ to obtain theoretical capacity. The initial lower capacity for the first 20 cycles is attributed to insufficient wetting.

We also demonstrate nanocomposites made of FGSs with hexagonal amorphous silica based on the surfactant mediated self-assembly, as shown in Figure $3 D, E$. Such composites are of interest in ultracapacitor applications and will be detailed elsewhere. In this example, a poly(ethylene glycol)- $b$-poly(propylene glycol)-b-poly(ethylene glycol) triblock copolymer (Pluronic $\mathrm{P} 123, \mathrm{EO}_{20} \mathrm{PO}_{70} \mathrm{EO}_{20}$ ) adsorbs onto graphene surfaces as hemimicelles ${ }^{48,49}$ to assist the self-assembly of nanostructured silica on the surfaces of the graphene material. The hexagonally packed nanostructured silica is more favorable using this surfactant as the structural directing agent, ${ }^{52}$ resulting in a three-dimensional interconnected network of graphene/graphene stacks and amorphous silica.

The layered metal oxide-graphene nanocomposites can also be produced as free-standing flexible films with the thickness ranging from 5 to $20 \mu \mathrm{m}$ by vacuum filtration..$^{58}$ These films are unique because they not only have the overall layer structure from twodimensional graphene but also have the locally ordered alternating layers of the graphene materials and metal oxide to ensure the conductivity and the structural integrity across the length scale from nanometer to micrometer. An SEM image of an $\mathrm{SnO}_{2}$ - graphene nanocomposite film, about $15 \mu \mathrm{m}$ thick, is shown in Fig- ure 4A. The nanocomposite film in the form of a disk with a diameter of $30 \mathrm{~mm}$ is robust and fairly flexible (the inset of Figure 4A). An SEM image of a polished cross-section (Figure 4B) reveals typical parallel, wavylayer architectures. A cross-sectional TEM image of the $\mathrm{SnO}_{2}$ - graphene nanocomposite film (Figure 4C) shows alternating layers of nanocrystalline $\mathrm{SnO}_{2}$ and graphene materials spanning the entire film.

The charge/discharge properties of the $\mathrm{SnO}_{2}$ - graphene nanocomposite film were investigated for use as anodes in Li-ion batteries. The freestanding $\mathrm{SnO}_{2}-$ graphene nanocomposite electrodes were studied using a half-cell design (Figure 4D) without using other carbon additive, polymer binder, or metal current collectors. The cell was charged/discharged between 0.02 and $1.5 \mathrm{~V}$ since this is the voltage range relevant to the anode materials in a full battery cell. The voltage-capacity profiles (Figure 4E) of the $\mathrm{SnO}_{2}$-graphene nanocomposite electrode at different current densities indicate good charge/discharge reversibility. The specific capacity of the $\mathrm{SnO}_{2}$ in the nanocomposite electrode as a function of cycle number is shown in Figure 4F. The discharge capacity drop in the first cycle is attributed to irreversible conversion of $\mathrm{SnO}_{2}$ to $\mathrm{Sn}$ and $\mathrm{Li}_{2} \mathrm{O}$ upon lithiation, ${ }^{59}$ as confirmed by the 
differential charge/discharge curves (Supporting Information, Figure S6). In the subsequent charge/discharge cycles, $\mathrm{Li}$ ions were reversibly inserted into $\mathrm{Sn}$ as $\mathrm{Li} / \mathrm{Sn}$ alloys ( $\mathrm{LiSn}$ or $\mathrm{Li}_{4.4} \mathrm{Sn}$ ) (Figure $\mathrm{S6}$ ). ${ }^{59}$ Within the first few cycles, the Coulombic efficiency was low because of poor electrolyte wetting of the dense $\mathrm{SnO}_{2}$-graphene nanocomposite electrode in the absence of polymer binder. The specific capacity gradually increases during the initial 10 cycles as the wetting improves and then levels off. A steady specific capacity of $\mathrm{SnO}_{2}(625 \mathrm{mAh} / \mathrm{g})$ is obtained after 10 cycles at a current density of $0.01 \mathrm{~A} / \mathrm{g}$ (Figure $4 \mathrm{~F}$, top). It is important to note that in the $\mathrm{SnO}_{2}-$ graphene nanocomposite that we studied, the electrochemically active phase for energy storage is mainly the $\mathrm{SnO}_{2}$, not the graphene. This work is different from other studies where graphene is the active material for energy storage. ${ }^{60,61}$ Graphene alone has a steady capacity of $120 \mathrm{mAh} / \mathrm{g}$ (Supporting Information, Figure S7) within the same voltage range at a current density of $0.004 \mathrm{~A} / \mathrm{g}$. As reported in the literature, graphene could also have a much higher capacity if charged to $3 \mathrm{~V}^{61}$ but the 0.02 - to $1.5-\mathrm{V}$ window is preferred because it is more relevant for the anode. At $40 \mathrm{wt} \%$, the graphene materials in the nanocomposite contribute to $48 \mathrm{mAh} / \mathrm{g}$ of capacity, so the overall capacity of the nanocomposite electrode is mostly from the $\mathrm{SnO}_{2}$ active phase. A steady specific capacity of $760 \mathrm{mAh} / \mathrm{g}$ for the nanocomposite electrode can be obtained at a current density of $0.008 \mathrm{~A} / \mathrm{g}$ (Figure $4 \mathrm{~F}$, bottom), close to the theoretical capacity $(780 \mathrm{mAh} / \mathrm{g})$. Specific capacities of 225 and $550 \mathrm{mAh} / \mathrm{g}$ are obtained at current densities of 0.08 and $0.02 \mathrm{~A} / \mathrm{g}$ (Figure 4F, bottom), respectively. $\mathrm{NiO}$ - graphene nanocomposite films were also investigated as electrodes for $\mathrm{Li}$-ion insertion/extraction (Supporting Information, Figure S8). The capacity of the $\mathrm{NiO}$ - graphene nanocomposite is more stable upon lithiation/delithiation over 100 cycles compared with typical capacity fading of $\mathrm{NiO}^{62} \mathrm{~A}$ gradual increase of the capacity can be also attributed to electrolyte wetting of the dense nanocomposite electrodes in the absence of a polymer binder. The improved cycling performance can be attributed similarly to good electrical contact between $\mathrm{NiO}$ and graphene in the layered nanocomposites during phase transformation of $\mathrm{NiO}$ upon lithiation/delithiation that usually leads to capacity fading. ${ }^{62}$

Graphene or graphene stacks can improve the electrochemical properties of the nanocomposites by improving the conductivity of the electrode materials and by stabilizing the electrode structure with a good electric contact between $\mathrm{SnO}_{2}$ and conductive graphene during the charge-discharge process. The effect of conductivity on electrode materials was discussed in a previous report. ${ }^{30} \mathrm{SnO}_{2}$ is a good high-capacity anode material for Li-ion batteries, but usually shows rapid capacity fading during charge/discharge cycles because of phase transformation and large-volume expansion upon lithiation. ${ }^{59}$ Therefore, the stability of the $\mathrm{SnO}_{2}$ electrode material is a much more serious problem and is emphasized in this paper. A high capacity has been reported in $\mathrm{SnO}_{2} / \mathrm{C}$ composites, but capacity fading is still significant in these studies..$^{31,63}$ Good capacity retention could be obtained using a much larger amount of carbon (above $60 \mathrm{wt} \%$ ) in the electrode. ${ }^{64}$ It should also be noted that in some studies, the electrode $\left(\mathrm{SnO}_{2}\right.$ or graphene materials) is charged to a high voltage (e.g., $0-3 \mathrm{~V}) .^{38,61}$ The higher voltage window will also give a higher capacity but may not be optimum for the $\mathrm{SnO}_{2}$ anode materials. In our study, we found out that both pure $\mathrm{SnO}_{2}$ nanocrystals and $\mathrm{SnO}_{2}-$ graphene composites prepared by mechanical mixing show capacity fading upon lithiation/delithiation (Supporting Information, Figure S9). Similarly, $\mathrm{SnO}_{2}$ nanoparticlegraphene nanocomposites with disordered structures reported previously also showed fading for the first 30 charge/discharge cycles. ${ }^{31}$ Our results demonstrate the potential of the self-assembly approach to obtain high capacity and better stability (no significant fading over 100 charge/discharge cycles) in the nanocomposite electrode due to the good contact between the nanocrystalline $\mathrm{SnO}_{2}$ and sandwiched graphene materials in the well-controlled layered nanostructures even after phase transformation and volume change upon lithiation/delithiation. We should be able to further improve the stability and rate performance by optimizing the dimension of graphene or graphene stacks and the compositions.

\section{CONCLUSIONS}

We have developed a ternary self-assembly approach to prepare metal oxide-graphene nanocomposites with well-controlled nanostructures using both molecular and extended nanoscale building blocks. A new class of layered nanocomposites has been formed containing stable, ordered, alternating layers of nanocrystalline metal oxide and graphene/graphene stacks. Alternatively the graphene materials can be incorporated into hexagonal nanostructures to form highsurface-area, conductive porous networks. The potential of such materials for energy storage is demonstrated. $\mathrm{SnO}_{2}-$ graphene nanocomposite films displayed near theoretical specific energy density for $\mathrm{Li}$ ion insertion/extraction without significant charge/ discharge degradation. The properties of different metal oxide-graphene nanocomposites for supercapacitor applications and for electrochemical catalysis are under investigation and will be reported in the future. The current work focuses on metal oxide-graphene nanocomposites, but the principle should be applicable to other nanoscale building blocks and compositions beyond metal oxides. 


\section{MATERIALS AND METHODS}

Synthesis of Metal Oxide - Graphene Nanocomposites. In a typical preparation of $\mathrm{SnO}_{2}$ - graphene (e.g., 28 wt \% graphene) nanocomposites, $71.3 \mathrm{mg}$ of functionalized graphene (Vor- $x$ from Vorbeck Materials) prepared by thermal expansion of graphite oxide and $12.2 \mathrm{~mL}$ of sodium 1-dodecanesulfonate aqueous solution $\left(20 \mathrm{mg} / \mathrm{mL}, 60{ }^{\circ} \mathrm{C}\right)$ were mixed together. The mixture was diluted to $30 \mathrm{~mL}$ and sonicated for 10-15 min (Branson Sonifer S-450A, $400 \mathrm{~W}$ ). A $10 \mathrm{~mL}$ portion of $0.12-\mathrm{M} \mathrm{SnCl}_{2}$ in 3.8 wt $\% \mathrm{HCl}$ solution was added into as-prepared graphenesurfactant dispersions with stirring. Then $4.8 \mathrm{~mL}$ of $1 \mathrm{M}$ urea was added dropwise under vigorous stirring followed by adding $4 \mathrm{~mL}$ of $\mathrm{H}_{2} \mathrm{O}_{2}$ solution ( $1 \mathrm{wt} \%$ ). Finally, the resulting mixture was diluted until it reached a total volume of $100 \mathrm{~mL}$. The mixture was further stirred in a sealed polypropylene flask at $90{ }^{\circ} \mathrm{C}$ for $16 \mathrm{~h}$

In a typical preparation of $\mathrm{NiO}$-graphene nanocomposite materials (e.g., 30wt \% graphene), $13 \mathrm{mg}$ of graphene and 1.5 $\mathrm{mL}$ of sodium dodecyl sulfate solution $(0.5 \mathrm{M})$ were mixed together. The mixture was diluted to $20 \mathrm{~mL}$ and sonicated for 10-15 min. Then $4.06 \mathrm{~mL}$ of $0.1 \mathrm{M} \mathrm{Ni}\left(\mathrm{NO}_{3}\right)_{2}$ solution was added dropwise under vigorous stirring followed by the addition of 7.29 $\mathrm{mL}$ of urea solution $(0.1 \mathrm{~g} / \mathrm{L})$ and $30 \mathrm{~mL}$ of deionized $\mathrm{H}_{2} \mathrm{O}$. The resulting mixture was further stirred in a sealed polypropylene flask at $90^{\circ} \mathrm{C}$ for $16 \mathrm{~h}$.

In a typical preparation of $\mathrm{MnO}_{2}$ - graphene nanocomposite materials (e.g., 60 wt \% graphene), $5 \mathrm{mg}$ of FGSs and $2.5 \mathrm{~mL}$ of sodium dodecyl sulfate solution $(0.5 \mathrm{M})$ were mixed together. The mixture was diluted to $20 \mathrm{~mL}$ and sonicated for 10 to $15 \mathrm{~min}$. A 6 mg portion of $\mathrm{KMnO}_{4}$ was dissolved in $10 \mathrm{~mL}$ of $0.1 \mathrm{M} \mathrm{Na}_{2} \mathrm{SO}_{4}$ solution. Then the solution was added dropwise to the surfactant-graphene dispersion under vigorous stirring for $2 \mathrm{~h}$.

The metal oxide-graphene nanocomposites were separated by centrifuge to obtain powder or by filtration to obtain free-standing films followed by washing with deionized $\mathrm{H}_{2} \mathrm{O}$. The obtained powder or films were then dried in a vacuum oven at $70{ }^{\circ} \mathrm{C}$ overnight and subsequently calcined in $2.7 \% \mathrm{H}_{2} / \mathrm{Ar}$ gas at $400{ }^{\circ} \mathrm{C}$ for $3 \mathrm{~h}$, respectively.

For synthesis of mesoporous graphene- $\mathrm{SiO}_{2}$ nanocomposites, $0.125 \mathrm{~g}$ of poly(ethylene glycol)- $b$-poly(propylene glycol)- $b$ poly(ethylene glycol) triblock copolymer (Pluronic P123, $\mathrm{EO}_{20} \mathrm{PO}_{70} \mathrm{EO}_{20}$, Sigma-Aldrich), $0.5 \mathrm{~mL}$ of tetraethyl orthosilicate (TEOS, Sigma-Aldrich), and $0.4 \mathrm{~g}$ of $0.1 \mathrm{M} \mathrm{HCl}$ were dissolved in $5 \mathrm{~mL}$ of ethanol. The solution was stirred for $30 \mathrm{~min}$. A total of $0.01 \mathrm{~g}$ of graphene was added into the solution followed by vig orous stirring for $15 \mathrm{~min}$. The mixture was added dropwise to a membrane filter under vacuum. The obtained black powders were dried overnight followed by calcination in static air at $400{ }^{\circ} \mathrm{C}$ for $2 \mathrm{~h}$. The weight percentage of $\mathrm{SiO}_{2}$ was estimated by TGA measurement.

Characterization. XRD patterns were obtained on a Philips Xpert $\mathrm{X}$-ray diffractometer using $\mathrm{Cu} \mathrm{K} \alpha$ radiation at $\lambda=1.54 \AA$. The metal oxide-graphene nanocomposite samples were embedded in resin (LR White Resin, Electron Microscopy Sciences) followed by aging at $60^{\circ} \mathrm{C}$ for $20 \mathrm{~h}$. The embedded samples were cross-sectioned by ultramicrotome for TEM studies. The TEM investigation was performed on a JEOL JSM-2010 TEM operated at 200 kV. SEM images were obtained on an FEI Helios Nanolab dual-beam focused ion beam/scanning electron microscope (FIB/SEM) operated at $2 \mathrm{kV}$.

The Li-ion battery electrochemical evaluations were carried out with a half-cell configuration using 2325 type coin cells. Li foil was used as counterelectrode and reference electrode. The heat-treated $\mathrm{SnO}_{2}$ - graphene nanocomposite paper electrode (40 wt \% graphene) was directly used as a working electrode. The electrolyte used was 1-M LiPF 6 in ethyl carbonate/dimethyl carbonate (volume ratio 1:1). The performance of the

$\mathrm{SnO}_{2}-$ graphene nanocomposite paper electrode was evaluated using Arbin Inst. (College Station, TX) at room temperature. The cells were tested between 0.02 and $1.5 \mathrm{~V}$ versus Li metal at various current densities. The specific capacity calculation was based on the $\mathrm{SnO}_{2}$ weight.

Acknowledgment. This work is supported by the LaboratoryDirected Research and Development Program at Pacific North- west National Laboratory (PNNL) and by the U.S. Department of Energy (DOE). The nanocomposite development was supported by the DOE Office of Basic Energy Sciences, Division of Materials Science and Engineering under Award KC020105-FWP12152.

The battery fabrication and testing was supported by the Office of Energy Efficiency and Renewable Energy. The TEM and SEM investigations were performed at the Environmental Molecular Sciences Laboratory, a national scientific-user facility sponsored by DOE's Office of Biological and Environmental Research and located at PNNL. PNNL is a multiprogram national laboratory operated for DOE by Battelle under Contract DE-AC05-76RL01830. IAA acknowledges support from ARO MURI under Grant No. W911NF-09-1-0476.

Supporting Information Available: Additional figures are provided, including XRD, electrochemical evaluation, Raman, and TEM results of the metal oxide-graphene nanocomposites. This material is available free of charge via the Internet at http:// pubs.acs.org.

\section{REFERENCES AND NOTES}

1. Decher, G. Fuzzy Nanoassemblies: Toward Layered Polymeric Multicomposites. Science 1997, 277, 1232-1237.

2. Balazs, A. C.; Emrick, T.; Russell, T. P. Nanoparticle Polymer Composites: Where Two Small Worlds Meet. Science 2006, 314, 1107-1110.

3. Ray, S. S.; Okamoto, M. Polymer/Layered Silicate Nanocomposites: A Review from Preparation to Processing. Prog. Polym. Sci. 2003, 28, 1539-1641.

4. Lu, Y. F.; Yang, Y.; Sellinger, A.; Lu, M. C.; Huang, J. M.; Fan, H. Y.; Haddad, R.; Lopez, G.; Burns, A. R.; Sasaki, D. Y.; Shelnutt, J.; Brinker, C. J. Self-Assembly of Mesoscopically Ordered Chromatic Polydiacetylene/Silica

Nanocomposites. Nature 2001, 410, 913-917.

5. Fan, H. Y.; Yang, K.; Boye, D. M.; Sigmon, T.; Malloy, K. J.; Xu H. F.; Lopez, G. P.; Brinker, C. J. Self-Assembly of Ordered, Robust, Three-Dimensional Gold Nanocrystal/Silica Arrays. Science 2004, 304, 567-571.

6. Zeng, H.; Li, J.; Liu, J. P.; Wang, Z. L.; Sun, S. H. ExchangeCoupled Nanocomposite Magnets by Nanoparticle SelfAssembly. Nature 2002, 420, 395-398.

7. Kotov, N. A.; Dekany, I.; Fendler, J. H. Ultrathin Graphite Oxide-Polyelectrolyte Composites Prepared by Self-Assembly: Transition between Conductive and Nonconductive States. Adv. Mater. 1996, 8, 637-641.

8. Podsiadlo, P.; Kaushik, A. K.; Arruda, E. M.; Waas, A. M.; Shim, B. S.; Xu, J. D.; Nandivada, H.; Pumplin, B. G.; Lahann, J.; Ramamoorthy, A.; Kotov, N. A. Ultrastrong and Stiff Layered Polymer Nanocomposites. Science 2007, 318, 8083.

9. Bonderer, L. J.; Studart, A. R.; Gauckler, L. J. Bioinspired Design and Assembly of Platelet Reinforced Polymer Films. Science 2008, 319, 1069-1073.

10. Vincent, J. F. V., Structural Biomaterials; Princeton Press: Princeton, NJ, 1990.

11. Kresge, C. T.; Leonowicz, M. E.; Roth, W. J.; Vartuli, J. C.; Beck, J. S. Ordered Mesoporous Molecular-Sieves Synthesized by a Liquid-Crystal Template Mechanism. Nature 1992, 359, 710-712.

12. Yang, P. D.; Zhao, D. Y.; Margolese, D. I.; Chmelka, B. F.; Stucky, G. D. Generalized Syntheses of Large-Pore Mesoporous Metal Oxides with Semicrystalline Frameworks. Nature 1998, 396, 152-155.

13. Zhao, D. Y.; Feng, J. L.; Huo, Q. S.; Melosh, N.; Fredrickson, G. H.; Chmelka, B. F.; Stucky, G. D. Triblock Copolymer Syntheses of Mesoporous Silica with Periodic 50 to 300 Angstrom Pores. Science 1998, 279, 548-552.

14. Braun, P. V.; Osenar, P.; Stupp, S. I. Semiconducting Superlattices Templated by Molecular Assemblies. Nature 1996, 380, 325-328.

15. Meng, Y.; Gu, D.; Zhang, F. Q.; Shi, Y. F.; Yang, H. F.; Li, Z.; Yu, C. Z.; Tu, B.; Zhao, D. Y. Ordered Mesoporous Polymers and Homologous Carbon Frameworks: Amphiphilic Surfactant Templating and Direct Transformation. Angew. Chem., Int. Ed. 2005, 44, 7053-7059. 
16. Li, D. L.; Zhou, H. S.; Honma, I. Design and Synthesis of Self-Ordered Mesoporous Nanocomposite through Controlled in Situ Crystallization. Nat. Mater. 2004, 3, 65-72.

17. Asefa, T.; MacLachan, M. J.; Coombs, N.; Ozin, G. A. Periodic Mesoporous Organosilicas with Organic Groups inside the Channel Walls. Nature 1999, 402, 867-871.

18. Iijima, S.; Ichihashi, T. Single-Shell Carbon Nanotubes of 1 nm Diameter. Nature 1993, 363, 603-605.

19. Thess, A.; Lee, R.; Nikolaev, P.; Dai, H. J.; Petit, P.; Robert, J.; Xu, C. H.; Lee, Y. H.; Kim, S. G.; Rinzler, A. G.; et al. Crystalline Ropes of Metallic Carbon Nanotubes. Science 1996, 273, 483-487.

20. Mamedov, A. A.; Kotov, N. A.; Prato, M.; Guldi, D. M.; Wicksted, J. P.; Hirsch, A. Molecular Design of Strong Single-Wall Carbon Nanotube/Polyelectrolyte Multilayer Composites. Nat. Mater. 2002, 1, 190-194.

21. Thostenson, E. T.; Ren, Z. F.; Chou, T. W. Advances in the Science and Technology of Carbon Nanotubes and Their Composites: A Review. Compos. Sci. Technol. 2001, 61, 1899-1912.

22. Meyer, J. C.; Geim, A. K.; Katsnelson, M. I.; Novoselov, K. S.; Booth, T. J.; Roth, S. The Structure of Suspended Graphene Sheets. Nature 2007, 446, 60-63.

23. Stankovich, S.; Dikin, D. A.; Dommett, G. H. B.; Kohlhaas, K. M.; Zimney, E. J.; Stach, E. A.; Piner, R. D.; Nguyen, S. T.; Ruoff, R. S. Graphene-Based Composite Materials. Nature 2006, 442, 282-286.

24. Geim, A. K.; Novoselov, K. S. The Rise of Graphene. Nat. Mater. 2007, 6, 183-191.

25. Berger, C.; Song, Z. M.; Li, X. B.; Wu, X. S.; Brown, N.; Naud, C.; Mayo, D.; Li, T. B.; Hass, J.; Marchenkov, A. N.; Conrad, E. H.; et al. Electronic Confinement and Coherence in Patterned Epitaxial Graphene. Science 2006, 312, 1191-1196.

26. Novoselov, K. S.; Geim, A. K.; Morozov, S. V.; Jiang, D.; Zhang, Y.; Dubonos, S. V.; Grigorieva, I. V.; Firsov, A. A. Electric Field Effect in Atomically Thin Carbon Films. Science 2004, 306, 666-669.

27. Li, X. L.; Wang, X. R.; Zhang, L.; Lee, S. W.; Dai, H. J. Chemically Derived, Ultrasmooth Graphene Nanoribbon Semiconductors. Science 2008, 319, 1229-1232.

28. Si, Y. C.; Samulski, E. T. Exfoliated Graphene Separated by Platinum Nanoparticles. Chem. Mater. 2008, 20, 6792-6797.

29. Xu, C.; Wang, X.; Zhu, J. W. Graphene-Metal Particle Nanocomposites. J. Phys. Chem. C 2008, 112, 19841-19845.

30. Wang, D.; Choi, D.; Li, J.; Yang, Z.; Nie, Z.; Kou, R.; Hu, D.; Wang, C.; Saraf, L. V.; Zhang, J.; et al. Self-Assembled $\mathrm{TiO}_{2}-$ graphene Hybrid Nanostructures for Enhanced Li-lon Insertion. ACS Nano 2009, 3, 907-914.

31. Paek, S. M.; Yoo, E.; Honma, I. Enhanced Cyclic Performance and Lithium Storage Capacity of $\mathrm{SnO}_{2} /$ Graphene Nanoporous Electrodes with ThreeDimensionally Delaminated Flexible Structure. Nano Lett. 2009, 9, 72-75.

32. Wang, X. R.; Tabakman, S. M.; Dai, H. J. Atomic Layer Deposition of Metal Oxides on Pristine and Functionalized Graphene. J. Am. Chem. Soc. 2008, 130, 8152-8153.

33. Nethravathi, C.; Rajamathi, J. T.; Ravishankar, N.; Shivakumara, C.; Rajamathi, M. Graphite OxideIntercalated Anionic Clay and Its Decomposition to Graphene-Inorganic Material Nanocomposites. Langmuir 2008, 24, 8240-8244.

34. Kong, B. S.; Geng, J. X.; Jung, H. T. Layer-by-Layer Assembly of Graphene and Gold Nanoparticles by Vacuum Filtration and Spontaneous Reduction of Gold lons. Chem. Commun. 2009, 2174-2176.

35. Zhou, X. Z.; Huang, X.; Qi, X. Y.; Wu, S. X.; Xue, C.; Boey, F. Y. C.; Yan, Q. Y.; Chen, P.; Zhang, H. In Situ Synthesis of Metal Nanoparticles on Single-Layer Graphene Oxide and Reduced Graphene Oxide Surfaces. J. Phys. Chem. C 2009, $113,10842-10846$.
36. Tarascon, J. M.; Armand, M. Issues and Challenges Facing Rechargeable Lithium Batteries. Nature 2001, 414, 359-367.

37. Simon, P.; Gogotsi, Y. Materials for Electrochemical Capacitors. Nat. Mater. 2008, 7, 845-854.

38. Wang, Y.; Zeng, H. C.; Lee, J. Y. Highly Reversible Lithium Storage in Porous $\mathrm{SnO}_{2}$ Nanotubes with Coaxially Grown Carbon Nanotube Overlayers. Adv. Mater. 2006, 18, 645-649.

39. Schniepp, H. C.; Li, J. L.; McAllister, M. J.: Sai, H.; HerreraAlonso, M.; Adamson, D. H.; Prud'homme, R. K.; Car, R.; Saville, D. A.; Aksay, I. A. Functionalized Single Graphene Sheets Derived from Splitting Graphite Oxide. J. Phys. Chem. B 2006, 110, 8535-8539.

40. McAllister, M. J.; Li, J. L.; Adamson, D. H.; Schniepp, H. C.; Abdala, A. A.; Liu, J.; Herrera-Alonso, M.; Milius, D. L.; CarO, R.; Prud'homme, R. K.; et al. Single Sheet Functionalized Graphene by Oxidation and Thermal Expansion of Graphite. Chem. Mater. 2007, 19, 4396-4404.

41. Si, Y.; Samulski, E. T. Synthesis of Water Soluble Graphene. Nano Lett. 2008, 8, 1679-1682.

42. Niyogi, S.; Bekyarova, E.; Itkis, M. E.; McWilliams, J. L.; Hamon, M. A.; Haddon, R. C. Solution Properties of Graphite and Graphene. J. Am. Chem. Soc. 2006, 128, 7720-7721.

43. Lomeda, J. R.; Doyle, C. D.; Kosynkin, D. V.; Hwang, W.-F.; Tour, J. M. Diazonium Functionalization of SurfactantWrapped Chemically Converted Graphene Sheets. J. Am. Chem. Soc. 2008, 130, 16201-16206.

44. Stankovich, S.; Piner, R. D.; Chen, X. Q.; Wu, N. Q.; Nguyen, S. T.; Ruoff, R. S. Stable Aqueous Dispersions of Graphitic Nanoplatelets via the Reduction of Exfoliated Graphite Oxide in the Presence of Poly(sodium 4-styrenesulfonate). J. Mater. Chem. 2006, 16, 155-158.

45. Xu, Y. X.; Bai, H.; Lu, G. W.; Li, C.; Shi, G. Q. Flexible Graphene Films via the Filtration of Water-Soluble Noncovalent Functionalized Graphene Sheets. J. Am. Chem. Soc. 2008, 130, 5856-5857.

46. Lotya, M.; Hernandez, Y.; King, P. J.; Smith, R. J.; Nicolosi, V.; Karlsson, L. S.; Blighe, F. M.; De, S.; Wang, Z.; McGovern, I. T.; et al. Liquid Phase Production of Graphene by Exfoliation of Graphite in Surfactant/Water Solutions. J. Am. Chem. Soc. 2009, 131, 3611-3620.

47. Li, X. L.; Zhang, G. Y.; Bai, X. D.; Sun, X. M.; Wang, X. R.; Wang, E.; Dai, H. J. Highly Conducting Graphene Sheets and Langmuir-Blodgett Films. Nat. Nanotechnol. 2008, 3, 538-542.

48. Atkin, R.; Warr, G. G. Self-Assembly of a Nonionic Surfactant at the Graphite/lonic Liquid Interface. J. Am. Chem. Soc. 2005, 127, 11940-11941.

49. Srinivas, G.; Nielsen, S. O.; Moore, P. B.; Klein, M. L. Molecular Dynamics Simulations of Surfactant SelfOrganization at a Solid-Liquid Interface. J. Am. Chem. Soc. 2006, 128, 848-853.

50. Huo, Q. S.; Margolese, D. I.; Ciesla, U.; Demuth, D. G.; Feng, P. Y.; Gier, T. E.; Sieger, P.; Firouzi, A.; Chmelka, B. F.; Schuth, F.; et al. Organization of Organic-Molecules with Inorganic Molecular-Species into Nanocomposite Biphase Arrays. Chem. Mater. 1994, 6, 1176-1191.

51. Lu, Y. F.; Ganguli, R.; Drewien, C. A.; Anderson, M. T.; Brinker, C. J.; Gong, W. L.; Guo, Y. X.; Soyez, H.; Dunn, B.; Huang, M. H.; et al. Continuous Formation of Supported Cubic and Hexagonal Mesoporous Films by Sol Gel DipCoating. Nature 1997, 389, 364-368.

52. Zhao, D.; Yang, P.; Melosh, N.; Feng, J.; Chmelka, B. F.; Stucky, G. D. Continuous Mesoporous Silica Films with Highly Ordered Large Pore Structures. Adv. Mater. 1998, 10, 1380-1385.

53. Kudin, K. N.; Ozbas, B.; Schniepp, H. C.; Prud'homme, R. K.; Aksay, I. A.; Car, R. Raman Spectra of Graphite Oxide and Functionalized Graphene Sheets. Nano Lett. 2008, 8, 36-41.

54. Schniepp, H. C.; Saville, D. A.; Aksay, I. A. Self-Healing of Surfactant Surface Micelles on Millisecond Time Scales. J. Am. Chem. Soc. 2006, 128, 12378-12379. 
55. Monnier, A.; Schuth, F.; Huo, Q.; Kumar, D.; Margolese, D.; Maxwell, R. S.; Stucky, G. D.; Krishnamurty, M.; Petroff, P.; Firouzi, A.; et al. Cooperative Formation of Inorganic-Organic Interfaces in the Synthesis of Silicate Mesostructures. Science 1993, 261, 1299-1303.

56. Wang, D. H.; Choi, D. W.; Yang, Z. G.; Viswanathan, V. V.; Nie, Z. M.; Wang, C. M.; Song, Y. J.; Zhang, J. G.; Liu, J. Synthesis and Li-lon Insertion Properties of Highly Crystalline Mesoporous Rutile $\mathrm{TiO}_{2}$. Chem. Mater. 2008, 20, 3435-3442.

57. Wang, D. H.; Ma, Z.; Dai, S.; Liu, J.; Nie, Z. M.; Engelhard, M. H.; Huo, Q. S.; Wang, C. M.; Kou, R. Low-Temperature Synthesis of Tunable Mesoporous Crystalline Transition Metal Oxides and Applications as Au Catalyst Supports. J. Phys. Chem. C 2008, 112, 13499-13509.

58. Dikin, D. A.; Stankovich, S.; Zimney, E. J.; Piner, R. D.; Dommett, G. H. B.; Evmenenko, G.; Nguyen, S. T.; Ruoff, R. S. Preparation and Characterization of Graphene Oxide Paper. Nature 2007, 448, 457-460.

59. Courtney, I. A.; Dahn, J. R. Electrochemical and in Situ X-ray Diffraction Studies of the Reaction of Lithium with Tin Oxide Composites. J. Electrochem. Soc. 1997, 144, 2045-2052.

60. Cassagneau, T.; Fendler, J. H. High Density Rechargeable Lithium-Ion Batteries Self-Assembled from Graphite Oxide Nanoplatelets and Polyelectrolytes. Adv. Mater. 1998, 10, 877-881.

61. Yoo, E.; Kim, J.; Hosono, E.; Zhou, H.-S.; Kudo, T.; Honma, I. Large Reversible Li Storage of Graphene Nanosheet Families for Use in Rechargeable Lithium Ion Batteries. Nano Lett 2008, 8, 2277-2282.

62. Poizot, P.; Laruelle, S.; Grugeon, S.; Dupont, L.; Tarascon, J. M. Nano-Sized Transition-Metaloxides as NegativeElectrode Materials for Lithium-Ion Batteries. Nature 2000, 407, 496-499.

63. Moon, T.; Kim, C.; Hwang, S. T.; Park, B. Electrochemical Properties of Disordered-Carbon-Coated $\mathrm{SnO}_{2}$ Nanoparticles for Li Rechargeable Batteries. Electrochem. Solid State Lett. 2006, 9, A408-A411.

64. Wang, Y.; Su, F. B.; Lee, J. Y.; Zhao, X. S. Crystalline Carbon Hollow Spheres, Crystalline Carbon-SnO ${ }_{2}$ Hollow Spheres, and Crystalline $\mathrm{SnO}_{2}$ Hollow Spheres: Synthesis and Performance in Reversible Li-Ion Storage. Chem. Mater. 2006, 18, 1347-1353. 